Article

\title{
Preparation and Thermal Properties of
} Molecular-Bridged Expanded Graphite/Polyethylene Glycol Composite Phase Change Materials for Building Energy Conservation

\author{
Dong Zhang, Meizhu Chen *, Quantao Liu, Jiuming Wan (1) and Jinxuan Hu \\ State Key Laboratory of Silicate Materials for Architectures, Wuhan University of Technology, \\ Wuhan 430070, China; pytmac@whut.edu.cn (D.Z.); liuqt@whut.edu.cn (Q.L.); wanjm@whut.edu.cn (J.W.); \\ hujinxuan221@whut.edu.cn (J.H.) \\ * Correspondence: chenmzh@whut.edu.cn; Tel.: +86-27-8716-2595
}

Received: 20 April 2018; Accepted: 12 May 2018; Published: 16 May 2018

\begin{abstract}
Using phase change materials (PCMs) in building envelopes became a reliable method to improve indoor comfort and reduce buildings' energy consumption. This research developed molecular-bridged expanded graphite (EG)/polyethylene glycol (PEG) composite PCMs (m-EPs) to conserve energy in buildings. The $\mathrm{m}$-EPs were prepared through a vacuum absorption technique, and a titanate coupling agent was used to build a molecular bridge between EG and PEG. SEM, mercury intrusion porosimetry (MIP), the leakage test, microcalorimetry, X-ray photoelectron spectroscopy (XPS), and Fourier transform infrared spectroscopy (FT-IR) were conducted to characterize the morphology, pore structure, absorbability, and modifying effects of the m-EPs. The phase change temperature, latent heat, thermal stability, and thermal conductivity of the m-EPs were determined by a differential scanning calorimeter (DSC), TGA, and a thermal constants analyzer. Results showed that the maximum mass ratio of PEG to EG without leakage was 1:7, and a stable connection was established in the m-EPs after modification. Compared with the unmodified EPs, the supercooling degree of the m-EPs reduced by about $3{ }^{\circ} \mathrm{C}$, but the latent heats and initial decomposition temperatures increased by approximately $10 \%$ and $20^{\circ} \mathrm{C}$, respectively, which indicated an improvement in the thermal energy storage efficiency. The thermal conductivities of the m-EPs were 10 times higher than those of the pristine PEGs, which ensured a rapid responding to building temperature fluctuations.
\end{abstract}

Keywords: expanded graphite; polyethylene glycol; phase change materials; titanate coupling agent; molecular bridge; building envelopes; thermal property; building energy conservation

\section{Introduction}

The rapid development of human civilization has led to a rising demand for energy. Statistics show that the global energy consumption reached $6.607 \times 10^{14} \mathrm{MJ}$ so far, and more than three-quarters of them are conventional fossil fuels (such as coal, petroleum oil, and natural gas) [1,2]. The extensive use of non-renewable energy leads to severe resource scarcity and environmental pollution problems [3]. On the other hand, the residential and commercial buildings consume almost $40 \%$ of the world's total energy usage for heating, ventilating, and air conditioning, which make it the leading energy consuming sector [4]. Therefore, exploiting green and energy-efficient buildings would be of benefit to the solution of energy and environment challenges facing the world. Applying phase change materials (PCMs) in building envelopes (such as wallboard [5], concrete [6], and insulation materials [7]) is a promising approach to decrease the energy consumption in buildings. The PCMs 
in building envelopes can spontaneously absorb thermal energy during hot daytime, and release thermal energy when the surrounding temperature dropped at nighttime. The phase transition of PCMs is a spontaneous process, and the phase transition temperature is constant. Therefore, using PCM-enhanced building envelopes to regulate temperature is an ideal way of improving the indoor comfort and conserving building energy.

Based on the phase transition modes, PCMs can be classified into different types such as solid-solid, solid-liquid, solid-gas, and liquid-gas [8]. Up to now, the solid-liquid type PCMs with the merits of volume stability, proper phase change temperatures, and lower cost have become the most widespread PCMs in building thermal management [9]. The solid-liquid PCMs can be categorized into inorganic, organic, and eutectic mixture according to their chemical compositions. The inorganic PCMs refer to various salt hydrates that have high thermal energy storage density, high thermal conductivity, and low cost. However, these materials are subject to many constraints such as corrosion, supercooling, and segregation during their service [8]. Comparatively, the organic PCMs, such as paraffins, carbohydrates, and derived lipids exhibit broader prospects due to their favorable chemical stability, heat of fusion, and resistances to supercooling and phase separation. Despite the flaws of low-thermal conductivity and liquid leakage, the organic PCMs are still the most widely used [10]. As for the eutectic mixture, it refers to a combination of two or more either organic or inorganic compounds, or a mixture of both [11]. The melting point of eutectics can be tailored to any desired temperature. However, the advantage of custom-tailoring also results in the high cost of eutectics, which is commonly two or three times greater than the organic or inorganic compounds.

As the most favorable PCMs in building envelopes, a host of attempts have been proposed to overcome the shortcomings of organic PCMs. Finned tubes [12], heat-conducting fillers [13], and a metal/graphite matrix [14] have been applied to enhance the thermal conductivity of organic PCMs. Meanwhile, the encapsulation approaches such as the in situ polymerization method [15], complex coacervation method [16], sol-gel method [17,18], and solvent extraction/evaporation method [19] were developed to fabricate form-stable PCMs (FSPCM). Among all of these performance-enhancing methods of organic PCMs, using expanded graphite (EG) as a matrix to absorb solid-liquid PCMs is an ideal way to enhance the heat transfer rate as well as prevent leakage. EG is a porous carbonaceous material with favorable absorbability, thermal conductivity, and chemical stability, and its applications on the encapsulation of PCMs has become a research focus in recent years. Scholars have conducted constructive studies on the fabrication and application of EG-based FSPCMs. Zhang et al. [20] and Sari et al. [21] verified the feasibility of applying EG as a heat transfer enhancer and shape stabilizer for paraffin PCMs. Xia et al. [22], Zeng et al. [23], Wang et al. [24], and Ling et al. [25] have separately applied various organic PCMs as functional components, and performed a series of tests on the morphologies, absorptive capacities, thermal conductivities, phase change temperatures, and enthalpies of the EG-based FSPCMs. Zhang et al. [26], Li et al. [27], and He et al. [28] incorporated different EG-based FSPCMs into cement mortars and evaluated their thermal energy storage performances. The results indicated that EG-based FSPCMs could reduce the indoor temperature variation and energy consumption of buildings.

Although the EG-based FSPCMs have been successfully applied in building envelopes, the liquid leakage and performance degradation are still inevitable to a certain extent, because the PCMs are bonded with the EG matrix only through weak physical connections (capillarity and van der Waals force). Meanwhile, few attempts have been made to enhance the interaction between EG and PCMs. Therefore, the objective of this research was to fabricate a novel EG-based FSPCM with strong chemical bonding. EG matrices with different particle sizes and pore structures were used to absorb polyethylene glycol (PEG). The optimal EG matrix for PEG absorption was determined by detecting the absorbability and weight loss of EG/PEG composite PCMs (EPs) under a high temperature. A titanate coupling agent KR-38S was employed to build a molecular bridge between an EG matrix and PEG. The modified EG matrix (m-EG) was prepared and mixed with five different PEGs to fabricate molecular-bridged EPs (m-EPs). Thermal properties, including the phase change temperature, supercooling degree, latent 
heat, heat transfer rate, and thermal reliability of m-EPs were characterized to demonstrate their performance improvement in this research.

\section{Materials and Methods}

\subsection{Materials}

Polyethylene glycols (PEGs, 98\%, chemical pure) with different relative molecular mass (800, 1000, 1500, 2000, and 3000, named as PEG $800, \mathrm{PEG}_{1000}, \mathrm{PEG}_{1500}, \mathrm{PEG}_{2000}$, and PEG 3000 , respectively) were supplied by Sinopharm Chemical Reagent Co., Ltd. (Wuhan, China). An isopropyl tri-(dioctylpyrophosphate) titanate coupling agent $\left(\mathrm{C}_{51} \mathrm{H}_{112} \mathrm{O}_{22} \mathrm{P}_{6} \mathrm{Ti}, \mathrm{KR}-38 \mathrm{~S}\right)$ was obtained from Kenrich Petrochemicals Inc. (New York, NY, USA). Expanded graphite (EG) with different particle sizes $\left(45 \mu \mathrm{m}, 75 \mu \mathrm{m}, 125 \mu \mathrm{m}, 180 \mu \mathrm{m}\right.$, and $300 \mu \mathrm{m}$, named as $\mathrm{EG}_{45}, \mathrm{EG}_{75}, \mathrm{EG}_{125}, \mathrm{EG}_{180}$, and $\mathrm{EG}_{300}$, respectively) were purchased from Qingdao Graphite Co., Ltd. (Qingdao, China). All of the materials were used as received without any further purification. The basic properties of PEGs and EGs were tested and demonstrated in Tables 1 and 2, respectively.

Table 1. Basic properties of the polyethylene glycols (PEGs) used in this research.

\begin{tabular}{cccccccc}
\hline Categories & $\boldsymbol{M} \boldsymbol{r}$ & $\boldsymbol{T}_{\text {onset- } \boldsymbol{m}}\left({ }^{\circ} \mathbf{C}\right)$ & $\boldsymbol{T}_{\text {onset-c }}\left({ }^{\circ} \mathbf{C}\right)$ & $\boldsymbol{\Delta T}\left({ }^{\circ} \mathbf{C}\right)$ & $\boldsymbol{\Delta} \boldsymbol{H}_{\boldsymbol{m}}(\mathrm{J} / \mathbf{g})$ & $\boldsymbol{\Delta} \boldsymbol{H}_{\boldsymbol{c}}(\mathrm{J} / \mathbf{g})$ & $\lambda(\mathrm{W} / \mathbf{m} \cdot \mathbf{K})$ \\
\hline PEG $_{800}$ & 800 & 21.79 & 23.56 & -1.77 & 143.51 & 126.63 & 0.2606 \\
$\mathrm{PEG}_{1000}$ & 1000 & 27.92 & 30.74 & -2.82 & 163.10 & 152.08 & 0.2790 \\
$\mathrm{PEG}_{1500}$ & 1500 & 43.36 & 31.04 & 12.32 & 170.34 & 159.24 & 0.3038 \\
$\mathrm{PEG}_{2000}$ & 2000 & 50.38 & 40.76 & 9.62 & 187.24 & 171.87 & 0.3151 \\
$\mathrm{PEG}_{3000}$ & 3000 & 55.15 & 43.24 & 11.91 & 186.50 & 160.86 & 0.3281 \\
\hline
\end{tabular}

Note: $M r$ : relative molecular mass; $T_{\text {onset- } m}$ : onset melting temperature; $T_{\text {onset-c }}$ : onset crystallization temperature; $\Delta T$ : supercooling degree, equals the temperature difference between $T_{\text {onset }-m}$ and $T_{\text {onset- } c} ; \Delta H_{m}$ : melting enthalpy; $\Delta H_{c}$ : crystallization enthalpy; $\lambda$ : thermal conductivity.

Table 2. Basic properties of expanded graphites (EGs) used in this research.

\begin{tabular}{ccccc}
\hline Categories & $\begin{array}{c}\text { Average Particle } \\
\text { Size }(\boldsymbol{\mu m})\end{array}$ & $\begin{array}{c}\text { Specific Surface } \\
\text { Area }\left(\mathbf{m}^{\mathbf{2}} \mathbf{g}\right)\end{array}$ & $\begin{array}{c}\text { Pore Volume } \\
\left(\mathbf{c m}^{\mathbf{3}} / \mathbf{g}\right)\end{array}$ & $\begin{array}{c}\text { Average Pore } \\
\text { Radius }(\boldsymbol{\mu m})\end{array}$ \\
\hline $\mathrm{EG}_{45}$ & 45 & 52.1099 & 1.4110 & 0.2101 \\
$\mathrm{EG}_{75}$ & 75 & 45.7174 & 3.2946 & 0.2584 \\
$\mathrm{EG}_{125}$ & 125 & 41.5314 & 7.1265 & 0.3152 \\
$\mathrm{EG}_{180}$ & 180 & 40.1269 & 7.7437 & 0.3273 \\
$\mathrm{EG}_{300}$ & 300 & 32.9647 & 9.2215 & 0.3439 \\
\hline
\end{tabular}

\subsection{Selection of EG Matrix for PEG Absorption}

Exploratory experiments were conducted to investigate the influence of PEGs molecular mass on the absorption capacity of EG. Results showed that no connection existed between the two. Therefore, $\mathrm{PEG}_{2000}$ was selected as a PCM in this section to explore the optimal EG particle size for PEG absorption and the maximum absorbability. The EG/PEG composite PCMs (EPs) were fabricated in the following steps. First, the EG matrix was desiccated in a vacuum oven at $90{ }^{\circ} \mathrm{C}$ in order to weigh it accurately. Afterwards, the weighted EG matrix was mixed with $\mathrm{PEG}_{2000}$ isopropanol solution proportionally by an ultrasonic oscillation at $70{ }^{\circ} \mathrm{C}$ for $15 \mathrm{~min}$; the oscillating frequency was $40 \mathrm{kHz}$. Finally, the mixtures were treated in a vacuum pump at $80^{\circ} \mathrm{C}$ for $4 \mathrm{~h}$, in order to vaporize the isopropanol solvents and absorb the melted $\mathrm{PEG}_{2000}$. The schematic for the preparation of EPs was shown in Figure 1.

The optimal particle size of EG for the absorption of PCMs was determined by a series of experiments. First, liquid leakage tests were conducted by spreading the EP samples on filter papers uniformly and heating them in a vacuum oven at $85^{\circ} \mathrm{C}$ for $1 \mathrm{~h}$. The weight loss and mass ratio of each sample were considered as the indicators to select an optimal EG matrix with favorable thermal stability and absorptivity. Subsequently, mercury intrusion porosimetry (MIP, AutoPore IV 9510, Micromeritics 
Instrument Corp., Norcross, GA, USA) and a scanning electron microscope (SEM, Quanta 450 FEG, FEI, Hillsboro, OR, USA) were employed to characterize the pore structure and morphology of each EG matrix and the corresponding EP. Finally, the optimal EG matrix was determined based on the aforementioned tests results.

\subsection{Preparation of Modifid EG (m-EG) and Molecular-Bridged EP (m-EP)}

The absorption and compatibility between an EG matrix and PCMs depend mainly on the functional groups on the EG surface, and it was critical to modify the EG according to the PCM category and working condition of the FSPCM. KR-38S is a titanate coupling agent with high coupling efficiency on polymers and inorganic fillers. The modification principle of KR-38S on the EG matrix in this research can be described as follows: the alkoxy groups of KR-38S react with the hydroxyl groups of the EG matrix to produce a monomolecular layer on the EG surface. When the PEG was mixed with the modified EG (m-EG), a transesterification reaction between KR-38S and the terminal hydroxyl groups of PEG (which have similar properties as alcoholic hydroxyls) could occur on the surface of m-EG; consequently, a strong combination between m-EG and PEG was established by using KR-38S as the molecular bridge.

The schematic of EG matrix modification was also shown in Figure 1. The EG matrix was dried in a vacuum oven at $90{ }^{\circ} \mathrm{C}$ for $16 \mathrm{~h}$ to remove moisture. Then, the isopropanol solutions with different KR-38S dosages ( $1 \mathrm{wt} \%, 2 \mathrm{wt} \%, 3 \mathrm{wt} \%$, and $4 \mathrm{wt} \%$ of EG) were prepared and mixed with the EG matrix. The mixing process was performed by ultrasonic oscillation at three different temperatures $\left(50{ }^{\circ} \mathrm{C}, 60{ }^{\circ} \mathrm{C}\right.$, and $70{ }^{\circ} \mathrm{C}$ ) to simulate different modifying conditions. The time and frequency of modifications were $15 \mathrm{~min}$ and $40 \mathrm{kHz}$, respectively. When the ultrasonic treatment was complete, the isopropanol solvents were vaporized in a vacuum pump at $80^{\circ} \mathrm{C}$ for $4 \mathrm{~h}$, and the modified EG matrix (m-EG) was fabricated. Microcalorimetry (C80, Setaram, Caluire, France) and X-ray photoelectron spectroscopy (XPS, ESCALAB 250Xi, Thermo Fisher Scientific, Waltham, MA, USA) were used to detect the isothermal calorimetric curve of each reaction and chemical state of the $\mathrm{m}$-EGs, in order to determine the optimal modifying condition.

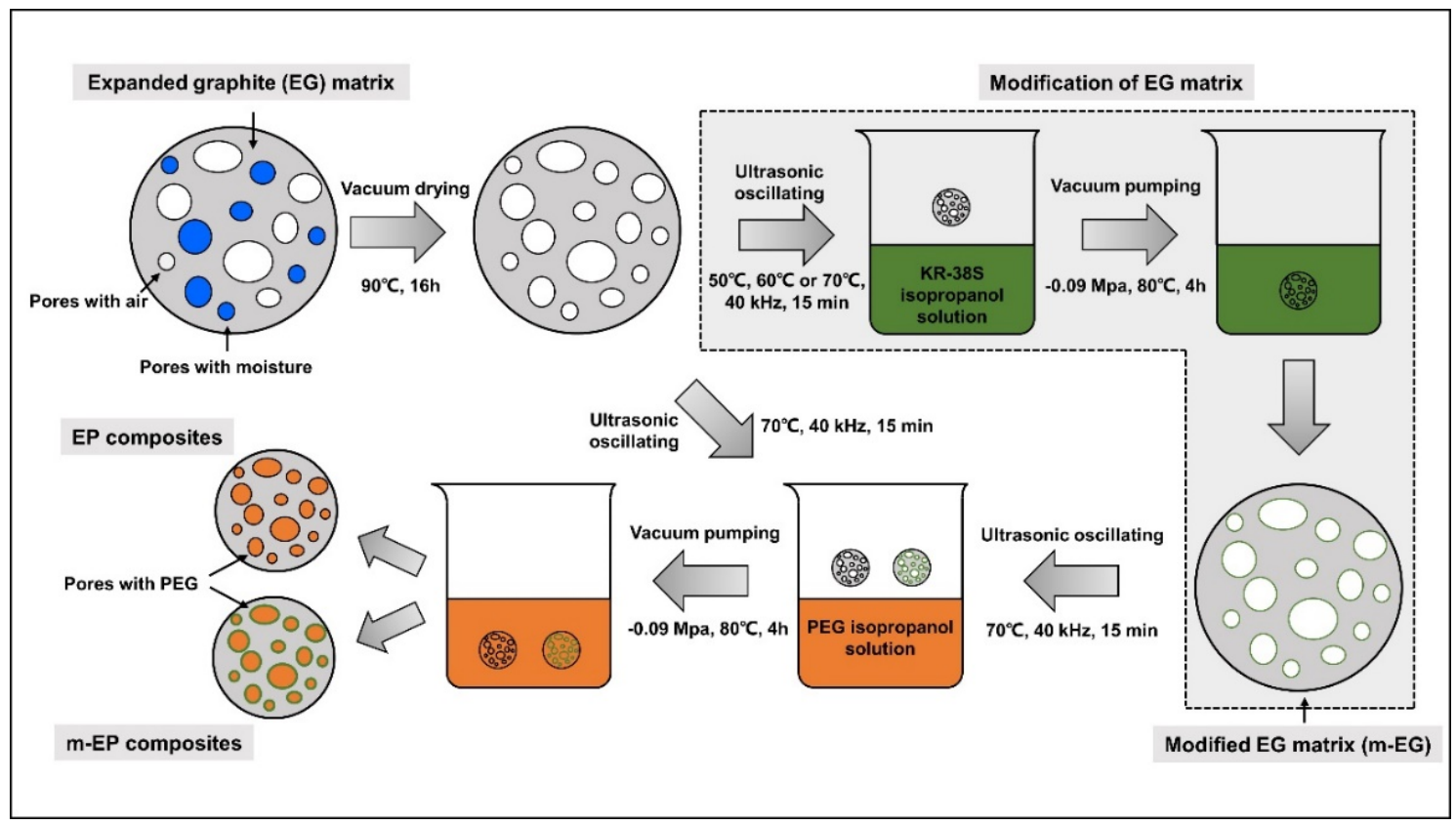

Figure 1. Schematic for the preparation of molecular-bridged EG/PEG composite phase change materials (m-EPs). 


\subsection{Characterization of $m-E P S$}

The properties of EPs and m-EPs were characterized in this section. The phase change temperatures and latent heats were investigated by a differential scanning calorimeter (DSC, Pyris1DSC, Perkin Elmer, Waltham, MA, USA). Indium was selected as a reference for instrument calibration. The heating rate was $1{ }^{\circ} \mathrm{C} / \mathrm{min}$, and the testing temperature range was $0-70{ }^{\circ} \mathrm{C}$. Fourier transform infrared spectroscopy (FT-IR, Nicolet ${ }^{\mathrm{TM}}$ 6700, Thermo Fisher Scientific, Waltham, MA, USA) was employed to manifest the chemical composition of EPs and m-EPs. The scanning range was from $4000 \mathrm{~cm}^{-1}$ to $400 \mathrm{~cm}^{-1}$ with a $4 \mathrm{~cm}^{-1}$ resolution. A thermogravimetric analyzer (TGA, STA449F3 Jupiter, NETZSCH, Bavaria, Germany) was used to compare the thermal stabilities of EPs and m-EPs. The measurements were conducted from the ambient temperature to $700{ }^{\circ} \mathrm{C}$ at a heating rate of $10{ }^{\circ} \mathrm{C} / \mathrm{min}$, the experimental atmosphere was $\mathrm{N}_{2}$, and the flow rate was $100 \mathrm{~mL} / \mathrm{min}$. Thermal conductivities were measured by using a thermal constants analyzer (TPS 2500S, Hot Disk, Goteborg, Sweden). Samples were prepared by a dry-pressing process with a cylindrical mold of $45 \mathrm{~mm}$ in diameter and $15 \mathrm{~mm}$ in height. The packing density of all of the samples was $1.13 \pm 0.02 \mathrm{~g} / \mathrm{cm}^{3}$, which was consistent with that of the pristine PEGs, in order to avoid the influence of packing density on thermal conductivity.

\section{Results and Discussion}

\subsection{Preparetion of $m-E P s$}

\subsubsection{Selection of EG Matrix}

Latent heat is critical for the application of PCMs; typically, a higher latent heat is beneficial for an efficient and economical utilization of building envelopes. Therefore, it is vital to incorporate more PEGs in the limited pore volumes of EG without degrading its performance. Five kinds of EG matrices were selected as the supporting materials to absorb $\mathrm{PEG}_{2000}$, and the mass ratios of EG and $\mathrm{PEG}_{2000}$ were 1:1, 1:2, 1:3, 1:4, 1:5, 1:6, 1:7, 1:8, 1:9, and 1:10, respectively. The leakage tests were performed to determine the optimal supporting material and the maximum absorbability. As presented in Figure 2, the weight loss percentages of five kinds EG matrices exhibited a similar trend that decreased initially and then increased, which indicated that each EG matrix had a certain absorbability. Specifically, the $\mathrm{EG}_{300}$ matrix exhibited the minimum weight loss percentage ( $5.66 \mathrm{wt} \%$ of $\mathrm{EP}$ ) when the EG/PEG mass ratio was 1:8, while both the minimum weight loss percentages of $\mathrm{EG}_{180}$ and $\mathrm{EG}_{125}$ (3.94 wt \% and $2.15 \mathrm{wt} \%$ of the corresponding EPs, respectively) were achieved when the EG/PEG mass ratio was 1:7. This phenomenon might be because $\mathrm{EG}_{300}$ possessed abundant pore volume compared with $\mathrm{EG}_{180}$ and $\mathrm{EG}_{125}$ (as seen in Table 2). Meanwhile, the macropores and mesopores in $\mathrm{EG}_{300}$ were more suitable for the adsorption of large molecules. Despite a higher absorbability, the weight losses of $\mathrm{EG}_{300}$ in each mass ratio were also higher in comparison with $\mathrm{EG}_{180}$ and $\mathrm{EG}_{125}$. Therefore, the packaging stability of the $\mathrm{EG}_{300}$ matrix was considered inferior to that of $\mathrm{EG}_{180}$ and $\mathrm{EG}_{125}$. Similarly, $\mathrm{EG}_{125}$ was a better supporting material than $\mathrm{EG}_{180}$ in this research. As for $\mathrm{EG}_{75}$ and $\mathrm{EG}_{45}$, their maximum EG/PEG mass ratios were both 1:4, and the weight losses increased dramatically when the mass ratios exceeded this threshold. This phenomenon can be explained by the limited amount of absorptive macropores and mesopores in $\mathrm{EG}_{75}$ and $\mathrm{EG}_{45}$ hindering the absorption of PEG. Hence, the $\mathrm{EG}_{125}$ matrix, which had the maximum EG/PEG mass ratio of 1:7, was considered as the optimal supporting material for PEG in this research.

The pore structure parameters and micromorphology of various EGs and the corresponding EPs with the maximum PEG absorption capacities are shown in Tables 3 and 4, respectively. As presented in Table 2, the specific surface areas of the EG matrices decreased as their particle sizes increased; however, the pore volumes and average pore radii exhibited the opposite tendencies. This could be because the higher expansion ratio of the large-sized EG particles resulted in an increase of macropores and mesopores for absorption, as well as a reduction in the amount of micropores that have large 
specific surface areas. When the maximum absorption capacities were achieved, the specific surface area, pore volume, and average pore radius of various EGs showed significant reductions, as illustrated in Table 3. These phenomena proved that the PEG was absorbed in the framework of the EG matrix. Furthermore, the leakage tests demonstrated that the maximum PEG absorption capacities increased from 1:4 to 1:8 as the EG particle size increased, and this trend was ascribed to the quantity variance of macropores.

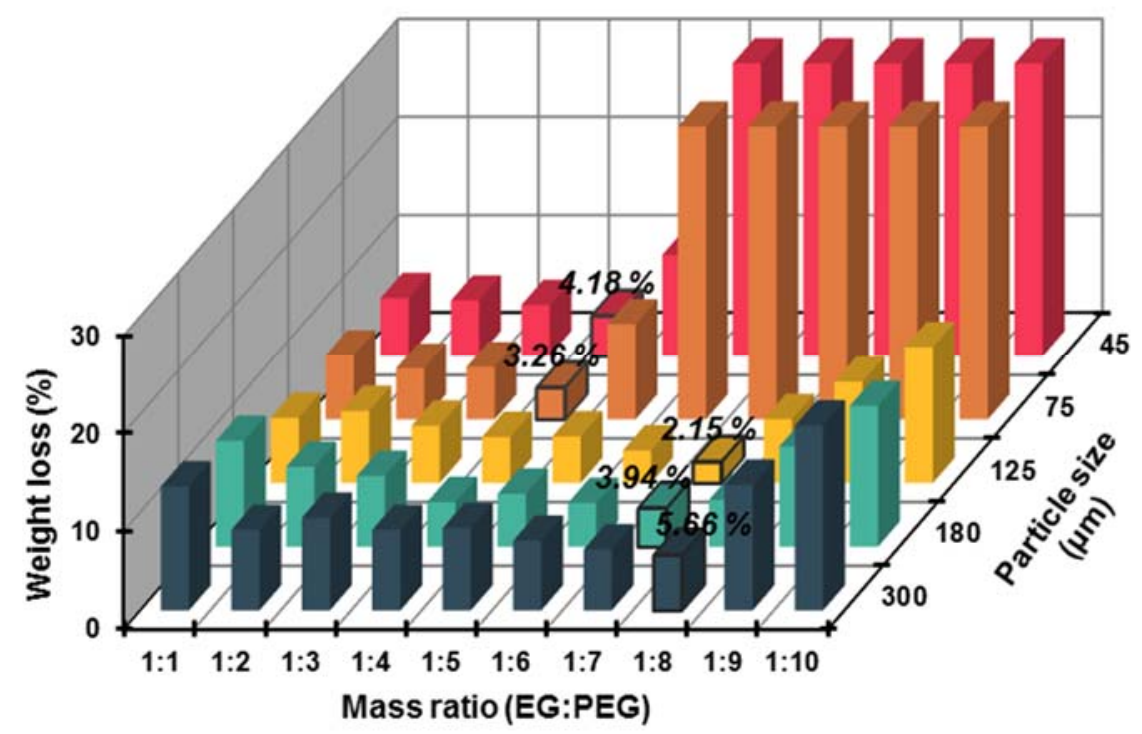

Figure 2. Weight loss of different EG/PEG composite phase change materials (EPs) after heat treatment.

The SEM images showed that all of the EG matrices had the worm-like structures, which were favorable to expanding the surface areas and enhancing the absorption capacities. It also can be noted that with the increase in EG particle size, the folding-type macropores, which ensured the great surface tension and capillary force of the EG matrix, were increased. These results were consistent with the outcomes of the pore structure analyses. As for the EPs, different features were exhibited in their morphologies. The surfaces of $\mathrm{EG}_{45}$ and $\mathrm{EG}_{75}$ were coated with massive PEG crystal when the mass ratios of EG/PEG were 1:4. On the other hand, when the absorption capacities of $\mathrm{EG}_{125}, \mathrm{EG}_{180}$, and $E_{300}$ were achieved, the frameworks of these EGs were still distinct, except for a slight amount of PEG crystal on the surface. Considering the variance in maximum absorption capacity, it can be concluded that the absorption of the $\mathrm{EG}_{45}$ and $\mathrm{EG}_{75}$ matrices to PEG was mainly depended on their extensive surface areas, while the massive macropore structures were responsible for the absorption of $E_{125}$, $\mathrm{EG}_{180}$, and $\mathrm{EG}_{300}$. It is also noteworthy that the worm-like structures of $\mathrm{EG}_{180}$ and $\mathrm{EG}_{300}$ were slightly damaged, owing to their high expansion ratios. These structural defects might be detrimental to the further processing of EPs. Therefore, based on the analyses of pore structures and morphologies, the $E_{125}$ matrix, which had the maximum PEG absorption capacity of 1:7, was determined to be the optimal supporting material in this research.

Table 3. Pore structure parameters of EGs with the maximum absorptive capacities.

\begin{tabular}{ccccc}
\hline Categories & $\begin{array}{c}\text { Specific Surface } \\
\text { Area }\left(\mathbf{m}^{\mathbf{2}} \mathbf{g}\right)\end{array}$ & $\begin{array}{c}\text { Pore Volume } \\
\left(\mathbf{c m}^{\mathbf{3}} \mathbf{g}\right)\end{array}$ & $\begin{array}{c}\text { Average Pore } \\
\text { Radius }(\boldsymbol{\mu m})\end{array}$ & $\begin{array}{c}\text { Maximum Mass Ratio } \\
\text { of EG to PEG }\end{array}$ \\
\hline $\mathrm{EG}_{45}$ & 21.5468 & 0.0954 & 0.0109 & $1: 4$ \\
$\mathrm{EG}_{75}$ & 24.3368 & 0.1089 & 0.0142 & $1: 4$ \\
$\mathrm{EG}_{125}$ & 17.6056 & 0.1354 & 0.0379 & $1: 7$ \\
$\mathrm{EG}_{180}$ & 15.3005 & 0.2025 & 0.0326 & $1: 7$ \\
$\mathrm{EG}_{300}$ & 14.5487 & 0.2944 & 0.0335 & $1: 8$ \\
\hline
\end{tabular}


Table 4. Micromorphologies of EGs before and after PEG absorption.

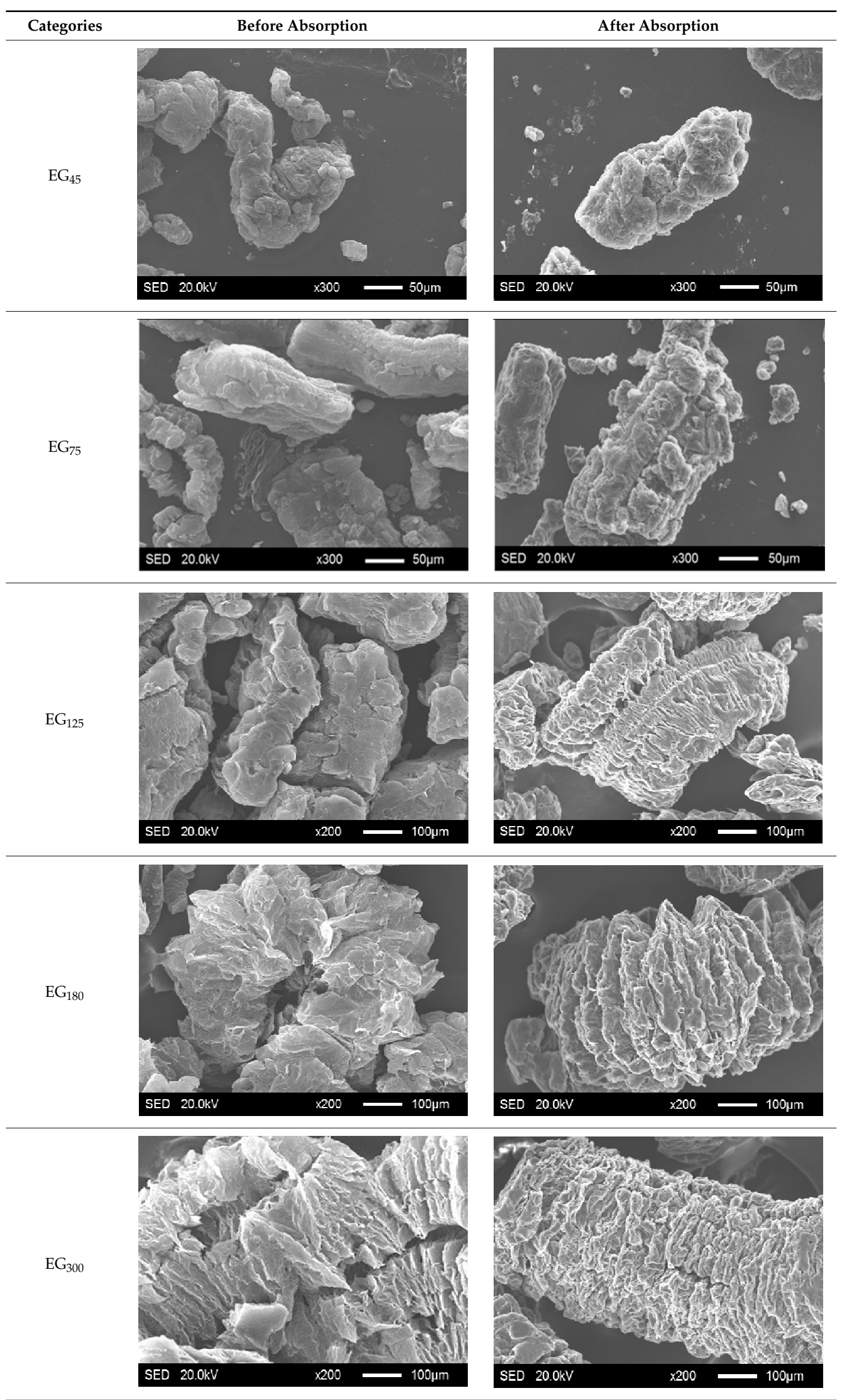




\subsubsection{Modification of EG Matrix}

The occurrence of chemical and physical reactions is always accompanied by the release or absorption of heat. Analyzing the heats would be helpful for determining the category and characteristic of the reactions. Figure 3 illustrated the isothermal calorimetric curves and binding energy values of EG-modifying reactions. As shown in the calorimetric curves of Figure 3, the reactions between EG and KR-38S were exothermic, and the shapes as well as the positions of the peaks varied with the KR-38S dosage and reaction temperature. These results indicated that the modifier was absorbed on the surface of the EG, and the absorption efficiencies were dependent on the modification conditions. To be specific, the binding energy values of the modifications at $50{ }^{\circ} \mathrm{C}$ were less than $10 \mathrm{~kJ} / \mathrm{mol}$, indicating that the coupling agent molecules were unactivated, and the physisorption (less than $40 \mathrm{~kJ} / \mathrm{mol}$ of binding energy) that was caused by the van der Waals force was dominant [29]. When the temperature increased to $60^{\circ} \mathrm{C}$, the binding energy of each sample exhibited a significant increase. It can be inferred that a chemisorption between the EG surface and the coupling agent molecules might have occurred. Furthermore, the binding energy at $60{ }^{\circ} \mathrm{C}$ initially increased, and decreased subsequently as the KR-38S dosage increased. This phenomenon can be explained by the modification being optimized when a monomolecular layer was created on the surface of the EG. Adding an excessive coupling agent that was hampered the chemical reaction between KR-38S and EG consequently resulted in the reduction of binding energy. As for the modifications at $70{ }^{\circ} \mathrm{C}$, the binding energy values demonstrated the same tendencies, but lower values in comparison with those at $60{ }^{\circ} \mathrm{C}$. The reason was that the modification temperature had exceeded the optimal activation temperature of KR-38S, and the chemisorptions were hindered. Therefore, it could be concluded from this section that the chemisorption could occur between the coupling agent and the EG matrix, and the optimal modifying condition was obtained by adding $3 \mathrm{wt} \%$ of KR-38S at $60{ }^{\circ} \mathrm{C}$. The chemisorptions enhanced the connection between the EG and PEGs, which was beneficial for improving the thermal stability and energy storage density of the m-EPs, as well as the energy conservation efficiency of the building envelopes.

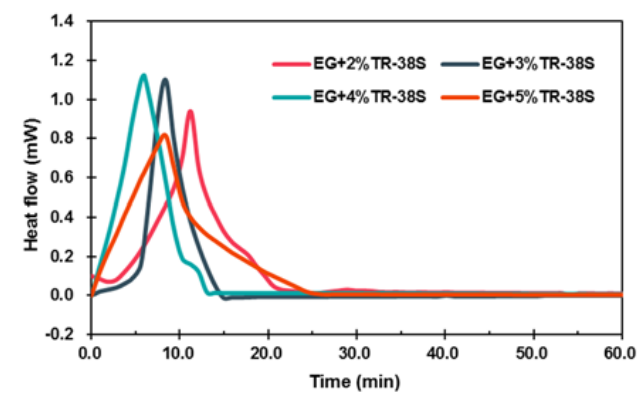

(a)

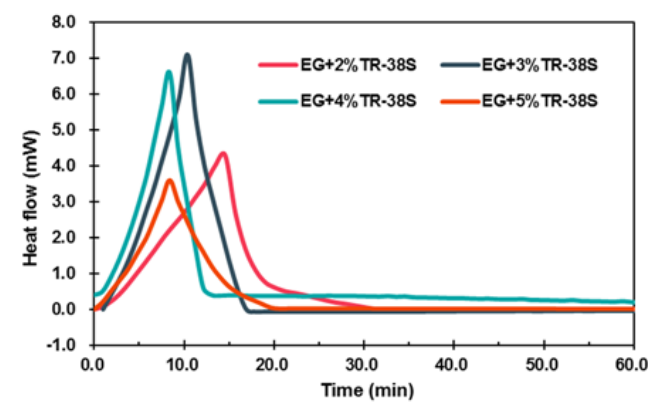

(c)

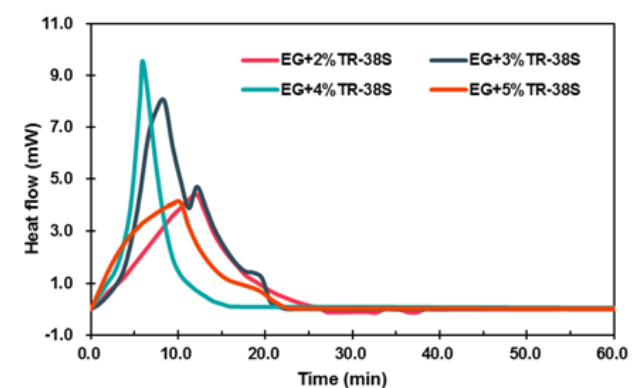

(b)

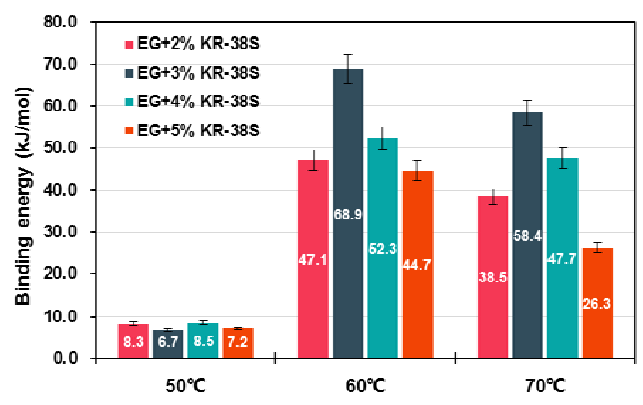

(d)

Figure 3. Calorimetric curves and binding energy values for the preparation of modified EGs (m-EGs). (a) calorimetric curves at $50{ }^{\circ} \mathrm{C}$; (b) calorimetric curves at $60{ }^{\circ} \mathrm{C}$; (c) calorimetric curves at $70{ }^{\circ} \mathrm{C}$; (d) binding energy of reactions. 
The XPS spectra of EG and m-EG are demonstrated in Figure 4. It was noticeable that two characteristic spectral peaks of O1s and C1s were illustrated in the spectrum of the EG matrix. The O1s was the oxidant residual during EG fabrication and adventitious carbon contamination in the atmosphere. Comparing with the EG matrix, the intensity of the O1s peak was obviously higher in the spectrum of the $\mathrm{m}-\mathrm{EG}$, and a new characteristic peak at $462.2 \mathrm{eV}$, corresponding to Ti2p, emerged. The peak table indicated that the oxygen element content in the EG matrix increased from 3.17 at \% to 11.21 at \% with the modification of KR-38S, and the titanium element was increased from 0.19 at $\%$ to 2.71 at \%. This indicated that the coupling agent was attached on the surface of the EG matrix. In order to better investigate the modification mechanism, the C1s spectra of the EG and m-EG was deconvoluted by using the Gauss-Lorentz function, and at the same time, the chemical state of the $\mathrm{C} 1 \mathrm{~s}$ electron was characterized [30]. It was obvious that two dominant peaks with bonding energies of $284.6 \mathrm{eV}$ and $285.5 \mathrm{eV}$, corresponding to $\mathrm{C}-\mathrm{C}$ and $\mathrm{C}-\mathrm{OH}$, respectively, were shown in the $\mathrm{C} 1$ s spectrum of the EG. The appearance of a C-OH peak indicated the existence of hydroxyl groups on the EG surface. Compared with EG, the C1s spectrum of m-EG exhibited another two peaks at $287.5 \mathrm{eV}$ and $288.9 \mathrm{eV}$ corresponding to $\mathrm{C}=\mathrm{O}$ and $\mathrm{O}=\mathrm{C}-\mathrm{OH}$, respectively. These new peaks were ascribed to the reactions between KR-38S and the EG matrix. The XPS results indicated that a satisfying modification effectiveness on the EG matrix was achieved, which was consistent with the conclusion of the microcalorimetry tests.

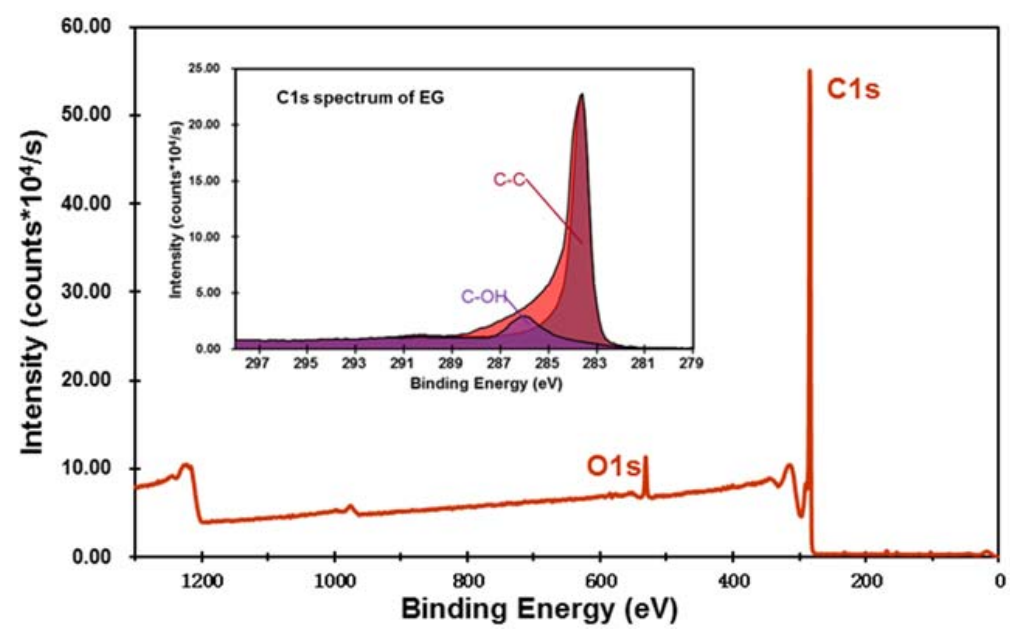

(a)

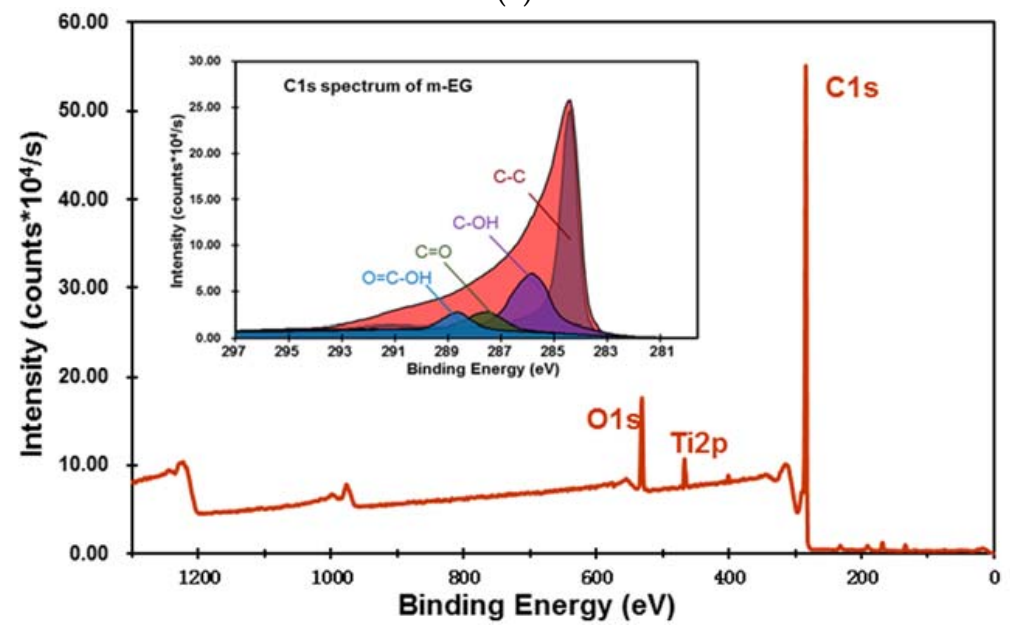

(b)

Figure 4. X-ray photoelectron spectroscopy (XPS) spectra of the EG matrix (a) and the m-EG matrix (b). 


\subsubsection{Preparation and Chemical Composition of m-EP}

The FT-IR spectra of the EG, m-EG, KR-38S, PEG, EP, and m-EP at the wavenumbers between $4000 \mathrm{~cm}^{-1}$ and $400 \mathrm{~cm}^{-1}$ were shown in Figure 5. From the spectrum of EG, three peaks at the wavenumbers of $1641 \mathrm{~cm}^{-1}, 1580 \mathrm{~cm}^{-1}$, and $1432 \mathrm{~cm}^{-1}$, which were caused by the stretching vibration of $\mathrm{C}=\mathrm{C}$, the stretching vibration of $\mathrm{C}=\mathrm{O}$, and the in-plane bending vibration of $-\mathrm{OH}$, respectively, could be noticed. As for the coupling agent KR-38S, the chief characteristic peaks that can be observed in the spectrum were the symmetrical and asymmetrical stretching vibrations of $-\mathrm{CH}_{3}$ at $2958 \mathrm{~cm}^{-1}$ and $2875 \mathrm{~cm}^{-1}$, respectively. Moreover, the symmetrical and asymmetrical deformation vibrations of $-\mathrm{CH}_{3}$ at $1464 \mathrm{~cm}^{-1}$ and $1386 \mathrm{~cm}^{-1}$ could also be detected. Furthermore, the characteristic peaks at $1036 \mathrm{~cm}^{-1}$ and $609 \mathrm{~cm}^{-1}$, corresponding to the vibrations of P-O and Ti-O, respectively, were critical for determining the type of coupling agent. When the modification of the EG matrix was performed, the four mentioned characteristic peaks belonging to the stretching and deformation vibrations of KR-38S appeared in the spectrum of m-EG matrix, but the in-plane bending vibration of -OH at $1432 \mathrm{~cm}^{-1}$ disappeared. This phenomenon could be because the peak position of the $-\mathrm{OH}$ in-plane bending vibration overlapped with the position of the symmetrical and asymmetrical deformation vibrations of $-\mathrm{CH}_{3}$.

Comparing the spectra of PEG and EP, it was notable that most of the characteristic peaks appeared in both spectra, except for some slight shifts. To be specific, the characteristic peaks at $845 \mathrm{~cm}^{-1}$ and $961 \mathrm{~cm}^{-1}$ corresponded to the bending vibrations of the $-\mathrm{CH}_{2} \mathrm{CH}_{2} \mathrm{O}-$ and $-\mathrm{C}-\mathrm{O}-\mathrm{C}$ - functional groups, respectively. The peaks at $1103 \mathrm{~cm}^{-1}$ and $1149 \mathrm{~cm}^{-1}$ were the stretching vibration of C-O. The peaks at the wavenumbers of $1242 \mathrm{~cm}^{-1}$ and $1281 \mathrm{~cm}^{-1}$ were the results of $-\mathrm{OH}$ symmetrical and asymmetrical stretching vibrations, respectively. The peaks at $1342 \mathrm{~cm}^{-1}$ and $1469 \mathrm{~cm}^{-1}$ represented the bending vibrations of the functional groups of $-\mathrm{CH}_{2}$ and $-\mathrm{OH}$, respectively. The similar FT-IR spectrum features between the EP and PEG indicated that the reaction between PEG and EG mainly depended on the capillary force and hydrogen bonding, rather than the chemical bonding. As for the m-EP, the characteristic peak at wavenumber of $1802 \mathrm{~cm}^{-1}$, representing the symmetrical stretching vibration of anhydride $\mathrm{C}=\mathrm{O}$, disappeared. However, a new peak belonging to the stretching vibration of ester $\mathrm{C}=\mathrm{O}$ appeared at $1781 \mathrm{~cm}^{-1}$. These results indicated that a transesterification between KR-38S and PEG might have occurred, and a chemical combination was established in m-EP.

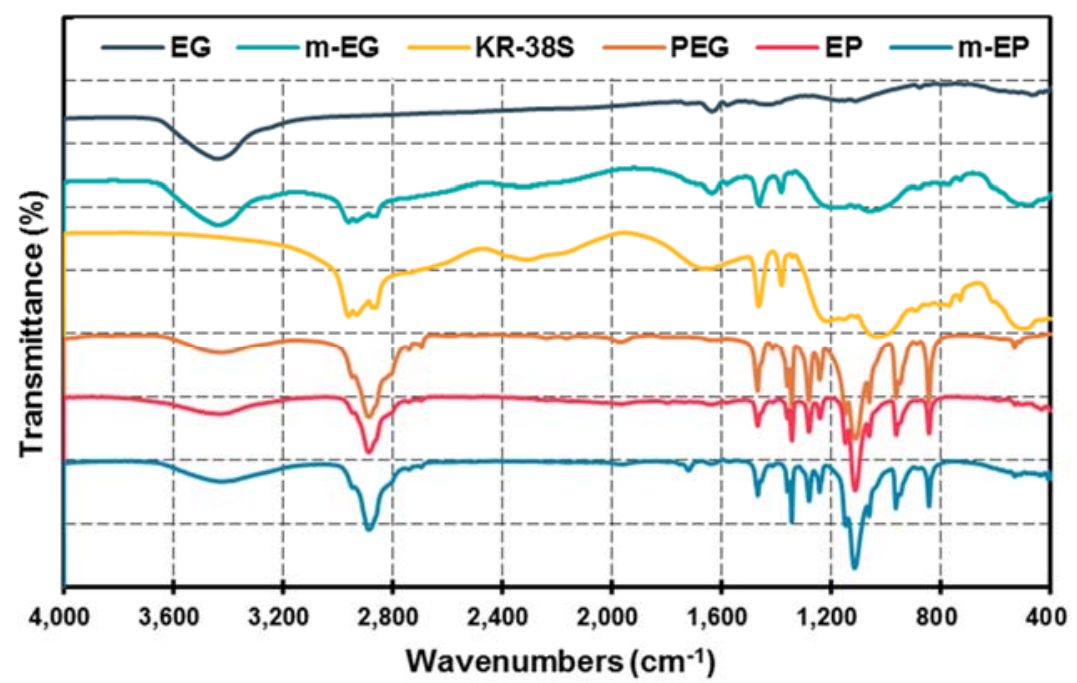

Figure 5. Fourier transform infrared (FT-IR) spectra of EG, the modified EG matrix (m-EG), KR-38S, PEG, EP, and m-EP. 


\subsection{Thermal Properties of $m$-EPS}

\subsubsection{Latent Heat and Phase Change Temperature}

Figure 6 demonstrated the DSC curves of the EPs and m-EPs. Their corresponding thermal properties are summarized in Table 5. As seen in Figure 6, the melting and crystallization temperatures of the EPs and m-EPs increased with the increase in the molecular mass of PEG. This feature was consistent with the trend of pristine PEG, indicating the successful incorporation of PEGs into the EG matrix. Meanwhile, the DSC curves of the $\mathrm{m}$-EPs were smoother, and the endothermic/exothermic peaks were narrower in comparison to those of the EPs. This result indicated that applying a m-EG was beneficial for the stabilization of the FSPCM phase change process in the building envelopes. Specifically, the EPs exhibited lower $T_{\text {onset }-m}$ and $T_{\text {onset-c }}$ values compared with those of the PEGs, because the crystallization-promoting effects of the EG surface accelerated the crystallization of PEGs [31]. Furthermore, the $T_{\text {onset- } m}$ and $T_{\text {onset-c }}$ of the $m$-EPs approached or even exceeded the pristine PEGs. The reason could be interpreted in two aspects: for the elevation of $T_{\text {onset-m }}$, the molecular bridge of the coupling agent enhanced the bonding between the PEGs and the EG matrix; hence, more energy was required to transform the PEG crystal to liquid. As for the crystallization process, the KR-38S molecule improved the compatibility between the PEGs and the EG surface, and consequently hindered the heterogeneous nucleation of the PEGs. The reduction of $\Delta T$ also supported this conclusion. Therefore, it can be concluded that the modification of the EG matrix improved the $T_{\text {onset- } m}, T_{\text {onset-c }}$, and $\Delta T$ of the m-EPs.

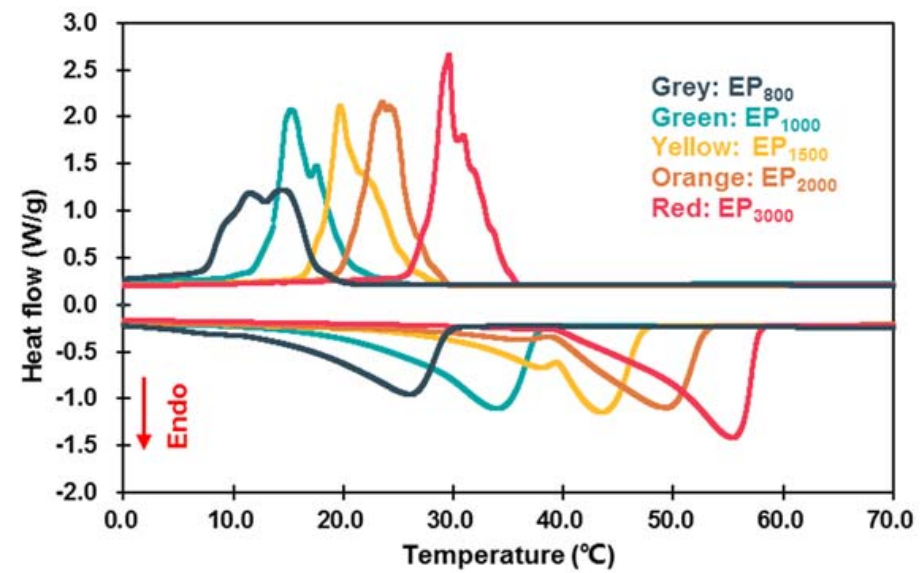

(a)

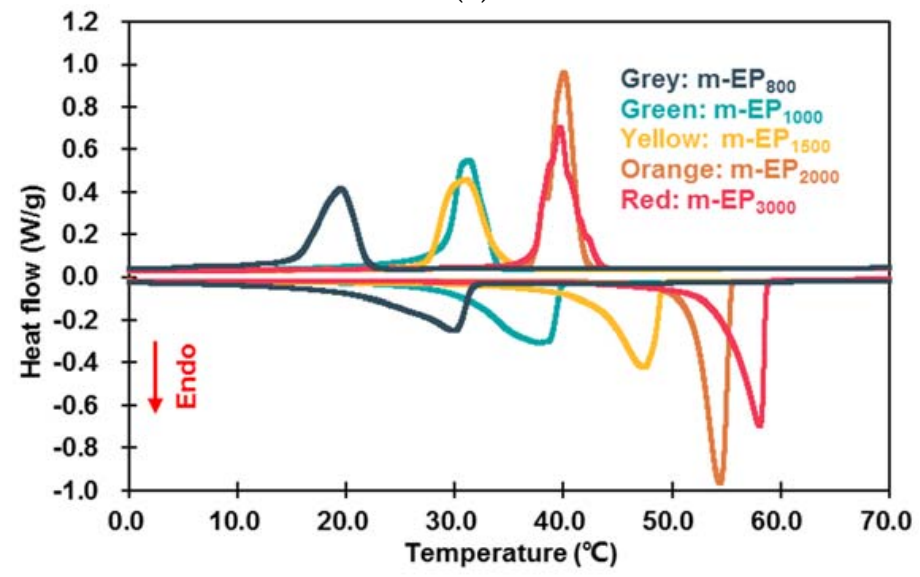

(b)

Figure 6. Differential scanning calorimeter (DSC) curves of EPs (a) and m-EPs (b). 
Table 5. Thermal properties of EPs and m-EPs.

\begin{tabular}{cccccccc}
\hline Categories & $\boldsymbol{T}_{\text {onset-m }}\left({ }^{\circ} \mathrm{C}\right)$ & $T_{\text {onset-c }}\left({ }^{\circ} \mathrm{C}\right)$ & $\Delta T\left({ }^{\circ} \mathrm{C}\right)$ & $\Delta H_{m}(\mathrm{~J} / \mathrm{g})$ & $\Delta \boldsymbol{H}_{c}(\mathrm{~J} / \mathrm{g})$ & $\eta_{m}(\%)$ & $\eta_{c}(\%)$ \\
\hline $\mathrm{EP}_{800}$ & 14.30 & 17.53 & -3.23 & 89.50 & 80.61 & 71.27 & 72.75 \\
$\mathrm{EP}_{1000}$ & 23.96 & 18.49 & 5.47 & 108.22 & 101.92 & 75.83 & 76.59 \\
$\mathrm{EP}_{1500}$ & 37.67 & 22.36 & 15.31 & 104.13 & 104.56 & 69.86 & 75.04 \\
$\mathrm{EP}_{2000}$ & 39.29 & 26.36 & 12.93 & 110.40 & 107.01 & 67.38 & 71.16 \\
$\mathrm{EP}_{3000}$ & 45.98 & 30.63 & 15.35 & 120.50 & 113.56 & 73.84 & 80.68 \\
$\mathrm{~m}_{-\mathrm{EP}}$ & 22.64 & 21.90 & 0.74 & 97.66 & 92.91 & 77.77 & 83.85 \\
$\mathrm{~m}_{80} \mathrm{EP}_{1000}$ & 30.18 & 33.64 & -3.46 & 121.89 & 116.80 & 85.41 & 87.77 \\
$\mathrm{~m}-\mathrm{EP}_{1500}$ & 42.67 & 33.93 & 8.74 & 122.94 & 114.88 & 82.48 & 82.45 \\
$\mathrm{~m}-\mathrm{EP}_{2000}$ & 51.95 & 41.66 & 10.29 & 143.79 & 137.53 & 87.77 & 91.45 \\
$\mathrm{~m}-\mathrm{EP}_{3000}$ & 54.63 & 41.27 & 13.36 & 141.60 & 124.12 & 86.77 & 88.18
\end{tabular}

Note: $\eta_{m}$ : melting enthalpy efficiency, $\eta_{m}=\frac{\Delta H_{m} \text { of EP or } \mathrm{m}-\mathrm{EP}}{\left(\Delta H_{m} \text { of PEG } \times(\mathrm{PEG} \% \text { in EP or } \mathrm{m}-\mathrm{EP})\right.} \times 100 \% ; \eta_{c}$ : crystallization enthalpy efficiency, $\eta_{c}=\frac{\Delta H_{c} \text { of EP or m-EP }}{\left(\Delta H_{c} \text { of PEG }\right) \times(\text { PEG } \% \text { in EP or } \mathrm{m}-\mathrm{EP})} \times 100 \%$.

As for the latent heats during phase change, the $\Delta H_{m}$ and $\Delta H_{c}$ of the EPs and m-EPs were lower than that of their corresponding PEGs. This was because the supporting materials in the composites couldn't store thermal energy. Meanwhile, the $\Delta H_{m}$ and $\Delta H_{c}$ of the m-EPs were higher than that of the EPs. This could be attributed to the additional amount of PEGs that anchored on the m-EG matrix due to the strong chemical bonding. Furthermore, the $\eta_{m}$ and $\eta_{c}$ of the EPs were $67.38-75.83 \%$ and $71.16-80.68 \%$, respectively, and the corresponding values for the m-EPs were $77.77-87.77 \%$ and $82.45-91.45 \%$. It could be noted that all of the melting and crystallization enthalpies of the EPs and $m$-EPs were lower than the theoretical latent heat values. This was because the PEGs couldn't be incorporated into the pore structure of the matrix, and the residual PEGs on the surface would vanish during phase transition. It was also noted that the $\eta_{m}$ values were lower than $\eta_{c}$ for both the EPs and the m-EPs, which could be ascribed to the inherent supercooling in the PEGs, as shown in the DSC curves. In conclusion, applying m-EGs as the supporting material could increase both the melting and crystallization enthalpies of the m-EPs by approximately $10 \%$, and the enhancement on thermal storage capacity would reduce the cost of m-EPs in buildings.

\subsubsection{Thermal Stability}

The thermal stability of EPs and m-EPs was evaluated by determining the mass loss. As the TGA curves illustrated in Figure 7 indicate, the EPs and m-EPs exhibited similar thermal stability characteristics. No decomposition occurred until the heating temperatures exceeded $300{ }^{\circ} \mathrm{C}$, and the decomposition completed at the temperatures of $420^{\circ} \mathrm{C}$. Based on the TGA curves of EPs and m-EPs, it could be inferred that the thermal stabilities of EG-based FSPCMs were satisfied at the intermediate low temperature. By comparing the initial decomposition temperatures (defined in this research as the temperature at which $10 \%$ of the weight was lost) of EPs and m-EPs, it could be noticed that the initial decomposition temperatures of the m-EPs were approximately $20^{\circ} \mathrm{C}$ higher than those of the EPs. This indicated that the modification endowed the m-EPs with better thermal stability, and these kinds of composite PCMs were able to embed in building materials under high temperatures. Furthermore, it is also worth noting that the residue of the EPs and m-EPs after TGA was about $13 \mathrm{wt} \%$, which was equivalent to the mass ratio of the supporting materials. 


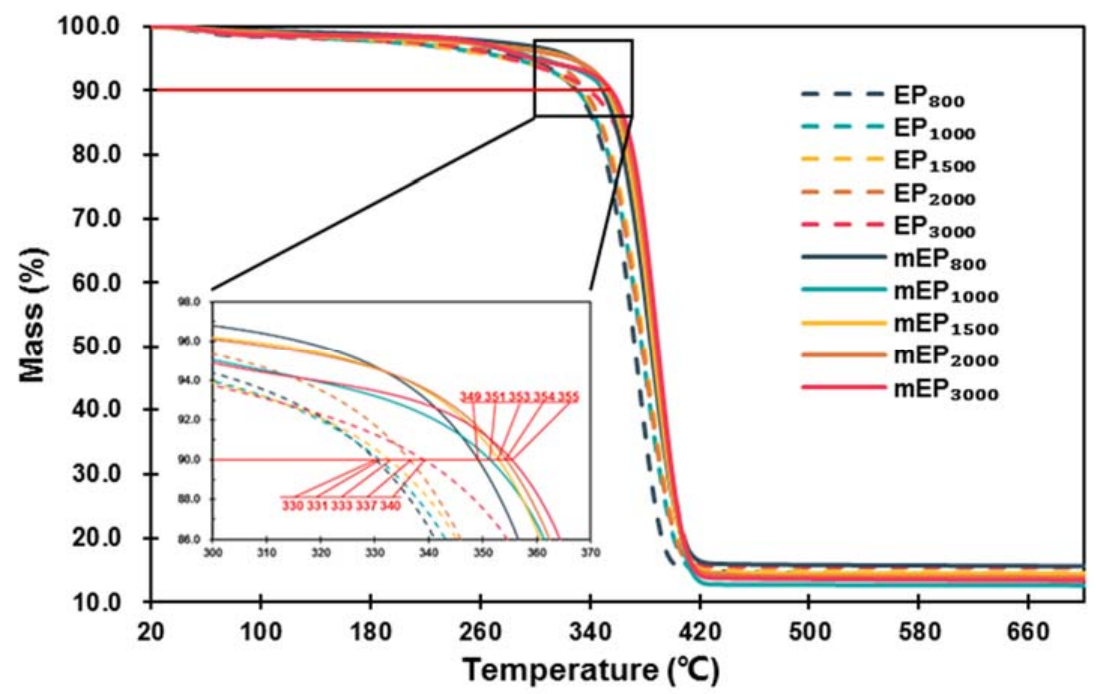

Figure 7. Thermogravimetric analyzer (TGA) curves of EPs and m-EPs.

\subsubsection{Thermal Conductivity}

The thermal conductivities of PEGs, E Ps, and m-EPs were shown in Figure 8. Packing density affects the thermal transfer rates of EG-based PCMs significantly due to the high porosity and thermal conductivity of the EG matrix. Therefore, the EPs and m-EPs were pressed to tablet samples, and their packing densities were consistent with the pristine PEGs. As illustrated in Figure 8, the measured thermal conductivities of pristine PEGs were as low as approximately $0.3 \mathrm{~W} / \mathrm{m} \cdot \mathrm{K}$, which was detrimental to the thermal energy storage efficiency in the building envelopes. When the EG matrix was applied, the thermal conductivities of EPs were increased significantly to about $3.5 \mathrm{~W} / \mathrm{m} \cdot \mathrm{K}$. This proved the enhancement of the EG matrix on the thermal transfer rate of the latent heat thermal energy storage system. Meanwhile, the thermal conductivity of the pristine PEGs increased with the increase in their molecular mass, and a similar tendency could be detected in the thermal conductivities of the EPs and $\mathrm{m}$-EPs. This result indicated that both the properties of the supporting and functional components determined the thermal performance of the FSPCMs. Furthermore, the thermal conductivity values of the m-EPs were slightly lower in comparison with those of the EPs. This might be because the modification of the organic coupling agent decreased the thermal transfer rate of the EG matrix to some extent. Even so, the thermal conductivities of the m-EPs were still 10 times higher than those of the pristine PEGs, which ensured a rapid response to the temperature fluctuations in the buildings.

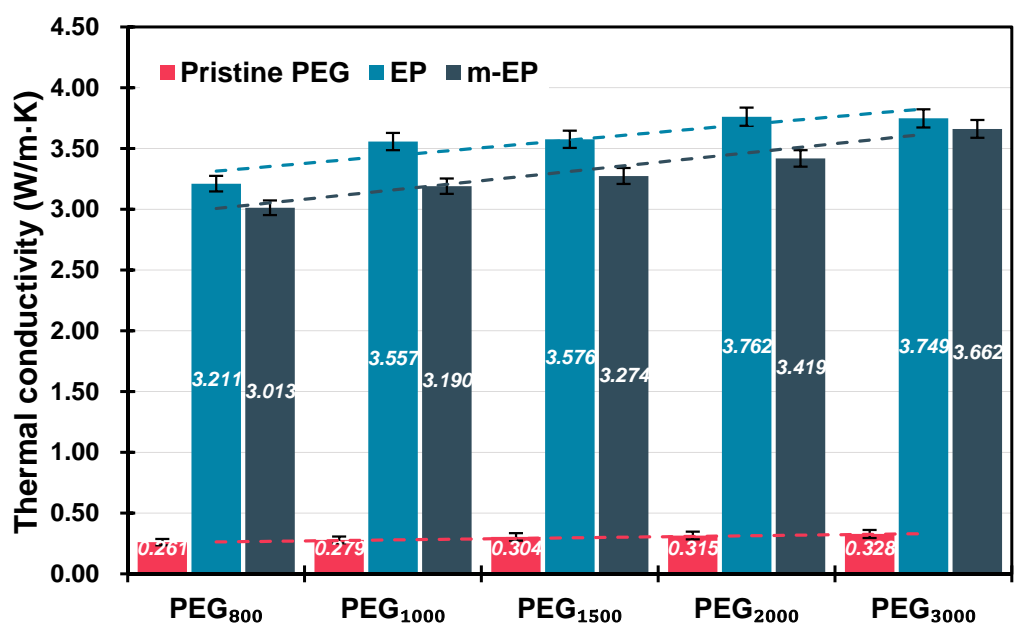

Figure 8. Thermal conductivity of PEGs, EGs, and m-EGs at the same packing density. 


\section{Conclusions}

An expanded graphite (EG)/polyethylene glycol (PEG) composite phase change material (PCM) was prepared for the purpose of bridging the gap between energy supply and demand in buildings. A titanate coupling agent KR-38S was used to build a molecular bridge between EG and PEG, and various thermal properties of the composite PCM were investigated in this paper. The following conclusions were drawn:

The EG matrix with macropores and mesopores was beneficial to the absorption of PEG. The optimal EG particle size for PEG absorption was determined as $125 \mu \mathrm{m}$, and the maximum mass ratio of PEG to EG was 1:7 in this research. The modification of KR-38S increased the quantity of the oxygen functional groups on the EG matrix, and a stable molecular bridge was established between the EG matrix and PEG. The optimal modification condition was obtained by adding $3 \mathrm{wt} \%$ of KR-38S at $60^{\circ} \mathrm{C}$. Compared with the EPs, the melting and crystallization temperatures of the m-EPs showed little variation, but the phase change temperature ranges and supercooling degree decreased significantly, indicating that the phase transition abilities of the EPs were enhanced after modification. The melting and crystallization enthalpies of the m-EPs increased by approximately $10 \%$, and the initial decomposition temperatures rose by about $20{ }^{\circ} \mathrm{C}$ in comparison with the EPs. These results indicated the improvements to the thermal energy storage efficiency and stability of the m-EPs, which are beneficial for the application of $\mathrm{m}$-EPs in building envelopes. The thermal conductivities of the $\mathrm{m}$-EPs were 10 times higher than those of the pristine PEGs. This result indicated that using $\mathrm{m}$-EPs in building envelopes could enhance the heat transfer rate as well as ensure a rapid response to temperature fluctuations.

In summary, using titanate coupling agent could build a molecular bridge in m-EPs, and improve the phase change temperature range, supercooling, heat storage density, thermal stability, and thermal conductivity of m-EPs. This research can benefit the application of PCMs in building energy conservation.

Author Contributions: M.C. and D.Z. conceived and designed the experiments; D.Z., J.H. and J.W. performed the experiments; M.C. and D.Z. analyzed the data; Q.L. contributed reagents/materials/analysis tools; D.Z. wrote the paper.

Funding: This research was funded by the National Natural Science Foundation of China (No. 51778515). The authors gratefully acknowledge their financial support.

Conflicts of Interest: There are no conflicts of interest regarding the publication of this paper.

\section{References}

1. EIA. International Energy Outlook 2017; U.S. Energy Information Administration: Washington, DC, USA, 2017.

2. BP. BP Energy Outlook 2017 Edition; BP PLC: London, UK, 2017.

3. Grimaud, A.; Rougé, L. Polluting non-renewable resources, innovation and growth: Welfare and environmental policy. Resour. Energy Econ. 2005, 27, 109-129. [CrossRef]

4. Qin, M.; Walton, G.; Belarbi, R.; Allard, F. Simulation of whole building coupled hygrothermal-airflow transfer in different climates. Energy Convers. Manag. 2011, 52, 1470-1478. [CrossRef]

5. Wang, E.; Kong, X.; Rong, X.; Yao, C.; Yang, H.; Qi, C. A study on a novel phase change material panel based on tetradecanol/lauric acid/expanded perlite/aluminium powder for building heat storage. Materials 2016, 9, 896. [CrossRef] [PubMed]

6. Šavija, B.; Zhang, H.; Schlangen, E. Influence of microencapsulated phase change material (PCM) addition on (Micro) mechanical properties of cement paste. Materials 2017, 10, e863. [CrossRef] [PubMed]

7. Ismail, K.A.R.; Castro, J.N.C. PCM thermal insulation in buildings. Int. J. Energy Res. 2015, 21, 1281-1296. [CrossRef]

8. Sharma, A.; Tyagi, V.V.; Chen, C.R.; Buddhi, D. Review on thermal energy storage with phase change materials and applications. Renew. Sustain. Energy Rev. 2009, 13, 318-345. [CrossRef]

9. Kuznik, F.; David, D.; Johannes, K.; Roux, J.J. A review on phase change materials integrated in building walls. Renew. Sustain. Energy Rev. 2011, 15, 379-391. [CrossRef] 
10. Akeiber, H.; Nejat, P.; Majid, M.Z.A.; Wahid, M.A.; Jomehzadeh, F.; Famileh, I.Z.; Calautit, J.K.; Hughes, B.R.; Zaki, S.A. A review on phase change material (PCM) for sustainable passive cooling in building envelopes. Renew. Sustain. Energy Rev. 2016, 60, 1470-1497. [CrossRef]

11. Raj, V.A.A.; Velraj, R. Review on free cooling of buildings using phase change materials. Renew. Sustain. Energy Rev. 2010, 14, 2819-2829. [CrossRef]

12. Shon, J.; Kim, H.; Lee, K. Improved heat storage rate for an automobile coolant waste heat recovery system using phase-change material in a fin-tube heat exchanger. Appl. Energy 2014, 113, 680-689. [CrossRef]

13. Li, M. A nano-graphite/paraffin phase change material with high thermal conductivity. Appl. Energy 2013, 106, 25-30. [CrossRef]

14. Mesalhy, O.; Lafdi, K.; Elgafy, A.; Bowman, K. Numerical study for enhancing the thermal conductivity of phase change material (PCM) storage using high thermal conductivity porous matrix. Energy Convers. Manag. 2005, 46, 847-867. [CrossRef]

15. Kuznik, F.; Virgone, J.; Johannes, K. In-situ study of thermal comfort enhancement in a renovated building equipped with phase change material wallboard. Renew. Energy 2011, 36, 1458-1462. [CrossRef]

16. Onder, E.; Sarier, N.; Cimen, E. Encapsulation of phase change materials by complex coacervation to improve thermal performances of woven fabrics. Thermochim. Acta 2008, 467, 63-72. [CrossRef]

17. Zhang, H.; Wang, X.; Wu, D. Silica encapsulation of n-octadecane via sol-gel process: A novel microencapsulated phase-change material with enhanced thermal conductivity and performance. J. Colloid Interface Sci. 2010, 343, 246-255. [CrossRef] [PubMed]

18. Ma, B.; Zhou, X.; Liu, J.; You, Z.; Wei, K.; Huang, X. Determination of specific heat capacity on composite shape-stabilized phase change materials and asphalt mixtures by heat exchange system. Materials 2016, 9 , 389. [CrossRef] [PubMed]

19. Yu, J.X.; Liu, T.Q. Preparation and characterization of microencapsulated phase change coating. Appl. Mech. Mater. 2013, 204-208, 4173-4176. [CrossRef]

20. Zhang, Z.; Fang, X. Study on paraffin/expanded graphite composite phase change thermal energy storage material. Energy Convers. Manag. 2006, 47, 303-310. [CrossRef]

21. Sarı, A.; Karaipekli, A. Thermal conductivity and latent heat thermal energy storage characteristics of paraffin/expanded graphite composite as phase change material. Appl. Therm. Eng. 2007, 27, 1271-1277. [CrossRef]

22. Xia, L.; Zhang, P.; Wang, R.Z. Preparation and thermal characterization of expanded graphite/paraffin composite phase change material. Carbon 2010, 48, 2538-2548. [CrossRef]

23. Zeng, J.L.; Gan, J.; Zhu, F.R.; Yu, S.B.; Xiao, Z.L.; Yan, W.P.; Zhu, L.; Liu, Z.Q.; Sun, L.X.; Cao, Z. Tetradecanol/expanded graphite composite form-stable phase change material for thermal energy storage. Sol. Energy Mater. Sol. Cells 2014, 127, 122-128. [CrossRef]

24. Wang, S.; Qin, P.; Fang, X.; Zhang, Z.; Wang, S.; Liu, X. A novel sebacic acid/expanded graphite composite phase change material for solar thermal medium-temperature applications. Sol. Energy 2014, 99, 283-290. [CrossRef]

25. Ling, Z.; Chen, J.; Xu, T.; Fang, X.; Gao, X.; Zhang, Z. Thermal conductivity of an organic phase change material/expanded graphite composite across the phase change temperature range and a novel thermal conductivity model. Energy Convers. Manag. 2015, 102, 202-208. [CrossRef]

26. Zhang, Z.; Shi, G.; Wang, S.; Fang, X.; Liu, X. Thermal energy storage cement mortar containing n-octadecane/expanded graphite composite phase change material. Renew. Energy 2013, 50, 670-675. [CrossRef]

27. Li, M.; Wu, Z.; Tan, J. Heat storage properties of the cement mortar incorporated with composite phase change material. Appl. Energy 2013, 103, 393-399. [CrossRef]

28. He, Y.; Zhang, X.; Zhang, Y.; Song, Q.; Liao, X. Utilization of lauric acid-myristic acid/expanded graphite phase change materials to improve thermal properties of cement mortar. Energy Build. 2016, 133, 547-558. [CrossRef]

29. Lüth, H. Surfaces and Interfaces of Solids; Springer: Berlin, Germany, 1995. 
30. Shirley, D.A. High-resolution x-ray photoemission spectrum of the valence bands of gold. Phys. Rev. B 1972, 5, 4709-4714. [CrossRef]

31. Xia, L.; Zhang, P. Thermal property measurement and heat transfer analysis of acetamide and acetamide/expanded graphite composite phase change material for solar heat storage. Sol. Energy Mater. Sol. Cells 2011, 95, 2246-2254. [CrossRef] 